\title{
The double tunnels technique: an alternative minimally invasive approach for carpal tunnel syndrome
}

\author{
Daniele Vanni, MD, ${ }^{1}$ Francesco Saverio Sirabella, MD, ${ }^{1}$ Renato Galzio, MD, ${ }^{2}$ Vincenzo Salini, MD, ${ }^{1}$ \\ and Vincenzo Magliani, MD ${ }^{3}$
}

\begin{abstract}
'Orthopaedic and Traumatology Department, "G. D’Annunzio" University, Chieti; ${ }^{2}$ Neurosurgery Department, "L'Aquila" University, L'Aquila; and 'Neurotraumatology and Vertebro-Medullary Surgery, "Renzetti” Hospital, Lanciano, Italy
\end{abstract}

\begin{abstract}
OBJECT The purpose of this study was to assess the effectiveness and safety of an alternative minimally invasive technique for the treatment of carpal tunnel syndrome (CTS).

METHODS This was designed as a prospective, randomized, open-label, blinded end point evaluation (PROBE) study. The active comparison was double tunnels technique (DTT) (Group A, 110 patients) versus standard open decompression of the median nerve (control [Group B], 110 patients). Patient recruitment started in January 2011. The primary outcomes were the functional Boston Carpal Tunnel Syndrome Questionnaire (BCTSQ) scores and visual analog scale (VAS) scores for pain (pVAS) at Weeks 2 and 4, and at Months 3,6, and 12. The secondary outcome was the aesthetics (aVAS) score at Weeks 2 and 4, and at Months 3, 6, and 12.
\end{abstract}

RESULTS The Student t-test and ANOVA were used, and the results were considered statistically significant if the $p$ value was $\leq 0.05$ for continuous variables. The DTT is a tissue-sparing approach that allows the surgeon to limit the length of the incision $(0.6 \pm 0.05 \mathrm{~cm})$ and to respect the palmar fascia and the subcutaneous tissue. Recovery from wrist pain, night pain, numbness, stiffness, and weakness was achieved more effectively and quickly compared with the standard approach. Better BCTSQ, pVAS, and aVAS scores were observed in Group A.

CONCLUSIONS The DTT is a safe and effective approach for the treatment of CTS. This technique entails faster recovery times, better aesthetic outcomes, and lower risks of complications.

http://thejns.org/doi/abs/10.3171/2014.11.JNS14901

KEY WORDS carpal tunnel syndrome; minimally invasive technique; tissue-sparing surgery; peripheral nerve

\footnotetext{
$\mathrm{C}$
} ARPAL tunnel syndrome (CTS) is the most common canalicular syndrome; approximately the $4 \%$ of the population is affected by this disease..$^{14}$ In many cases the origin may remain poorly defined, although the pathophysiological mechanism of this disease is clear. Conservative treatment is usually ineffective, and therefore surgical treatment becomes necessary. ${ }^{12}$ Several surgical techniques have been described. Open neurolysis of the median nerve was performed for the first time in 1924 by Mackinnon, and in 1950 Phalen et al..$^{25}$ made this approach very widespread. Actually, open neurolysis of the median nerve is the most common technique, ${ }^{31}$ although it may be associated with several complications (adhesions, hypertrophic scar, pillar pain, long healing period, and flexor tendon bowstringing)..$^{10,11,31}$ To reduce the risk of complications, several alternative approaches were de- veloped. In recent years, minimally invasive approaches and endoscopy have become widely used, although they are not free from potential complications. , $13,20,22,24,33$ In this prospective, randomized, open-label, blinded end point evaluation (PROBE) study, the safety and efficacy of the double tunnels technique (DTT), an alternative minimally invasive approach for CTS, were evaluated.

\section{Methods}

Study Design

This was designed as a PROBE study. The active comparison was DTT (Group A) versus standard open decompression of the median nerve (Group B). Patient recruitment started in January 2011. All patients were informed about the study procedures and they signed an informed

ABBREVIATIONS aVAS, pVAS = aesthetic visual analog scale, pain VAS; BCTSQ = Boston Carpal Tunnel Syndrome Questionnaire; CTS = carpal tunnel syndrome; DTT = double tunnels technique; PF = palmar fascia; PROBE = prospective, randomized, open-label, blinded end point evaluation; TCL = transverse carpal ligament. SUBMITTED April 23, 2014. ACCEPTED November 12, 2014.

INCLUDE WHEN CITING Published online May 29, 2015; DOI: 10.3171/2014.11.JNS14901.

DISCLOSURE The authors report no conflict of interest concerning the materials or methods used in this study or the findings specified in this paper. 
consent form. Ethical approval was obtained from the ethics clearance committee of the health administration at "Renzetti" Hospital.

\section{Patient Inclusion and Exclusion Criteria}

Adult patients (18 years or older) affected by CTS were eligible for participation in this trial.

\section{General Inclusion Criteria}

Inclusion criteria included a clinical diagnosis of CTS, suspected on the basis of symptoms (dysesthesia, paresthesia, and hypesthesia in the innervation territory of the median nerve) and signs (Phalen test and/or positive Tinel test, prehension deficiency), and confirmed by 1) an electromyography study; 2) previous treatment with the same pharmacological (NSAIDs) and physical therapy (ultrasound and low-level laser) options administered for at least 6 months without improvement; or 3) a Bland score ${ }^{3}$ greater than or equal to 3 (according to the Bland neurophysiological classification).

\section{General Exclusion Criteria}

The exclusion criteria were anatomical variations of the median nerve and the surrounding structures, flexor tenosynovitis, and incidental space-occupying lesions ${ }^{16}$ identified by an ultrasound wrist scan; a history of or current associated upper-limb injuries due to orthopedic, neurological, rheumatological, or metabolic disorders (e.g., diabetes mellitus, thyroid diseases); pregnancy; or Body Mass Index greater than 30.

\section{Randomization Protocol}

The patients who fit the inclusion criteria (220 patients: 58 men and 162 women, mean age 55.4 years) were randomized to 2 different groups. Patients in Group A received DTT: 110 patients, mean male/female ratio 1:2.79, mean age 55.8 years, and mean Bland score 4.25. Patients in Group B (control) were treated with standard open median nerve decompression: 110 patients, mean male/ female ratio 1:2.81, mean age 54.9 years, and mean Bland score 4.03 (Table 1). Both the patients and the treating surgeon were aware of treatment assignment, which was unknown until inclusion and randomization. During the follow-up period, the participants were evaluated by the same blinded observer (who was different from both the surgeon and the observer appointed to wound care), which was possible because the patients were instructed to cover their scar with a sticking plaster before the examination.

\section{Study Outcomes}

The primary outcomes were the functional Boston Carpal Tunnel Syndrome Questionnaire (BCTSQ) scores and visual analog scale (VAS) scores for pain (pVAS) at Weeks 2 and 4, and at Months 3, 6, and 12. Secondary outcome was the aesthetics (aVAS) score at Weeks 2 and 4, and at Months 3, 6, and 12.

\section{Statistical Analysis}

Statistical analyses were performed independently by a nonclinical investigator assistant. The Student t-test and
TABLE 1. General characteristics and physical examination findings in both groups of patients with CTS

\begin{tabular}{lcc}
\hline \multicolumn{1}{c}{ Characteristic } & Group A & Group B \\
\hline No. of patients & 110 & 110 \\
\hline Mean M/F ratio & $1: 2.79$ & $1: 2.81$ \\
\hline Mean age (yrs) & 55.8 & 54.9 \\
\hline Bland score (no. of patients) & & \\
\hline 3 & 33 & 41 \\
\hline 4 & 32 & 36 \\
\hline 5 & 29 & 21 \\
\hline 6 & 16 & 12 \\
\hline Mean & 4.25 & 4.03 \\
\hline CTS & & \\
\hline Right & 83 & 86 \\
\hline Left & 18 & 17 \\
\hline Bilat & 9 & 7 \\
\hline Tinnel sign & 92 & 86 \\
\hline Phalen sign & 103 & 99 \\
\hline Muscle atrophy \& weakness & 52 & 48 \\
\hline Numbness & 59 & 54 \\
\hline
\end{tabular}

ANOVA were used, and results were considered statistically significant if the $\mathrm{p}$ value was $\leq 0.05$ for continuous variables. The data were analyzed using standard statistical software.

\section{Postoperative Indications}

All patients received the same postoperative protocol: a compression bandage of the treated wrist for 3 days; pharmacological therapy (NSAIDs, a single dose per day) for 1 week; sticking plaster replacement every 3 days; and stitches removed after 12 days. In these cases, the wound care was performed by another observer different both from the surgeon and from the observer appointed to conduct the postoperative score evaluation in a blinded fashion. The patients were instructed not to perform activities that required a complete wrist flexion or extension, or those requiring repetitive movements of fingers or prolonged isometric grip for the first 15 days.

\section{Surgical Technique}

All the surgical procedures, both the DTT and the standard technique, were performed by the same surgeon.

\section{Double Tunnels Technique}

All procedures were performed under local anesthesia (carbocaine 2\%,5 ml) and using an upper-arm tourniquet. A longitudinal skin incision approximately $0.6 \pm 0.05 \mathrm{~cm}$ (Figs. 1 and 2) was made distally to the proximal wrist crease, along a longitudinal line virtually drawn from the third finger web space to the wrist. ${ }^{1,5}$ To our knowledge, the other minimally invasive techniques require larger incisions. After the skin was incised, a couple of retractors were placed perpendicular to the incision to expose a layer of subcutaneous fat. Subsequently, 2 small Ragnell retrac- 

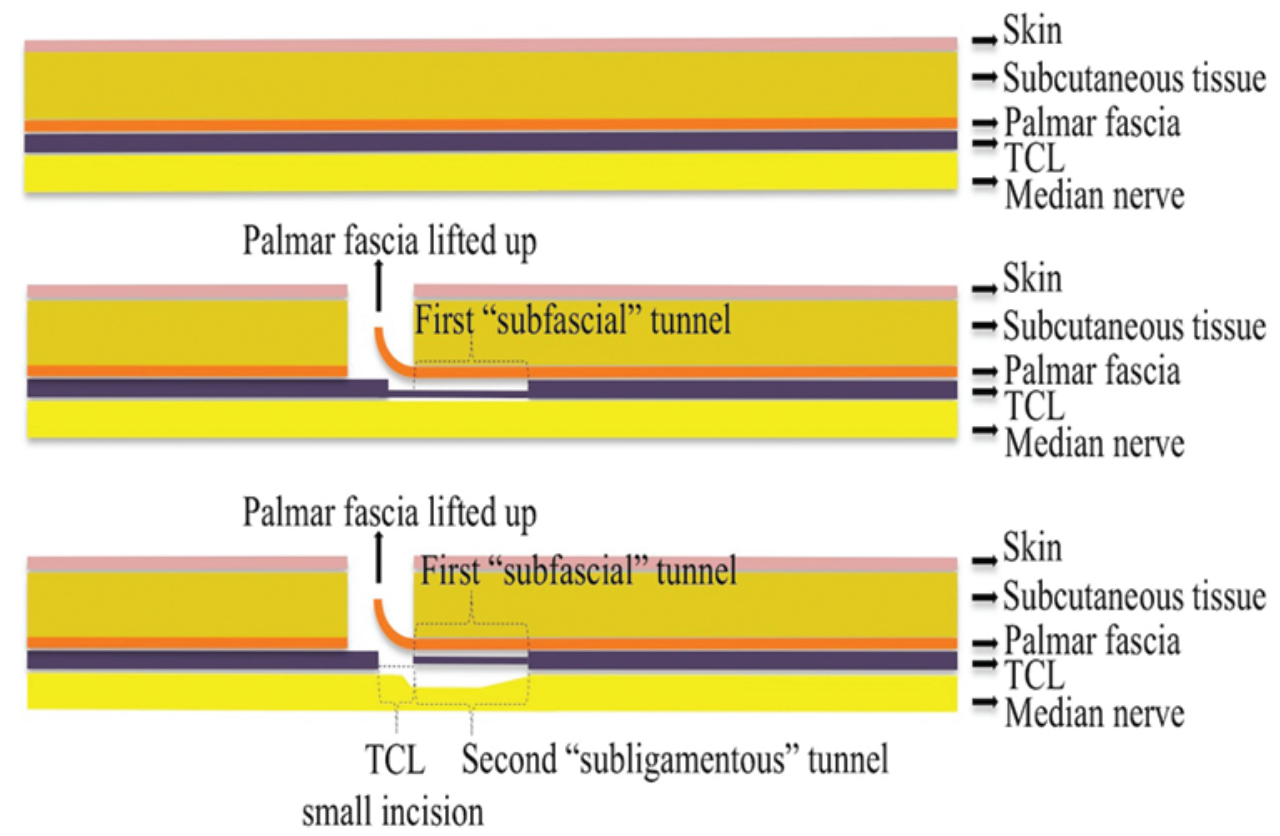

FIG. 1. Schematic diagram of surgical technique. Figure is available in color online only.

tors (3 mm width) (Fig. 3) were placed parallel to the incisions (Fig. 4).

Once the palmar fascia (PF) was identified, a small transverse incision (about $5 \mathrm{~mm}$ ) was done where the antebrachial fascia continued with the PF. In this way the PF was lifted up (Fig. 5) to create the first "subfascial" tunnel between the PF, which was maintained intact, and the transverse carpal ligament (TCL). Subsequently, the proximal edge of the TCL was cut through a small incision (about $5 \mathrm{~mm}$ ) (Fig. 6) and the second "subligamentous" tunnel between the TCL and median nerve was obtained

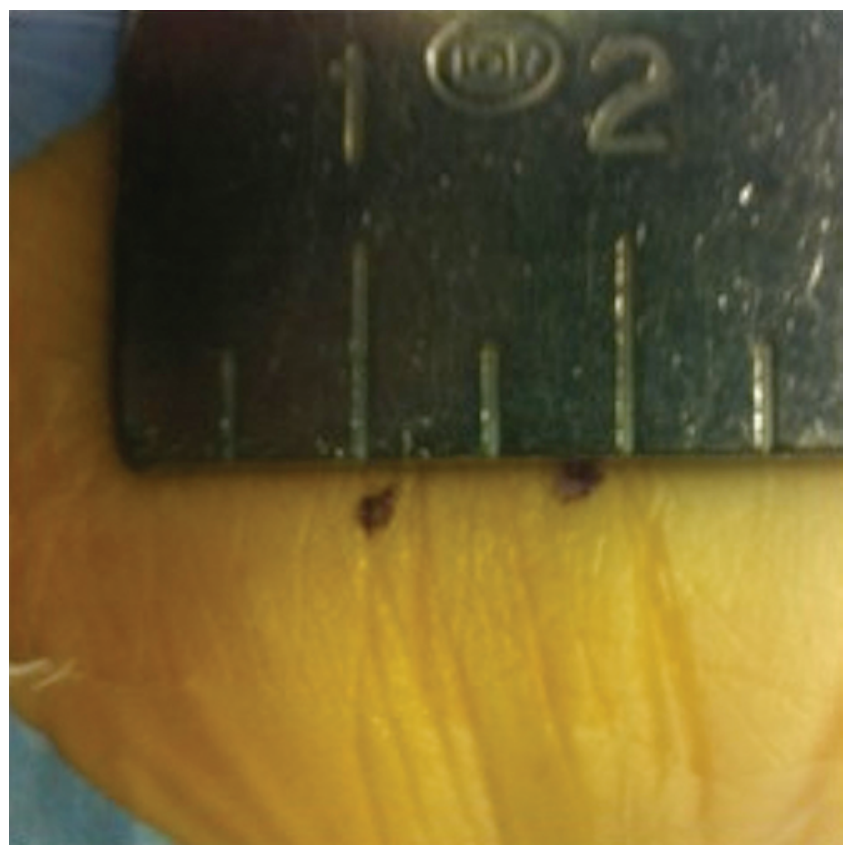

FIG. 2. Photograph showing marks for a 6 -mm longitudinal skin incision. Figure is available in color online only.
(Fig. 7). The tunnels were both created by blunt dissection and in the direction of the third web space.

The blunt jaws of the dissecting scissors (Fig. 8) were then inserted in this so-called anatomical binary (Fig. 9). Along the longitudinal line virtually drawn from the third web space to the wrist, the TCL was completely divided (Fig. 10). Although the ligament was sliced blindly, it was performed within the safe zone according to the Martin classification. 1,5,23 To avoid iatrogenic damage to the nerves, it is enough to respect certain anatomical criteria. Watchmaker ${ }^{35}$ et al. showed that the palmar cutaneous branch of the median nerve appears $2.09 \pm 0.31 \mathrm{~cm}$ from the distal

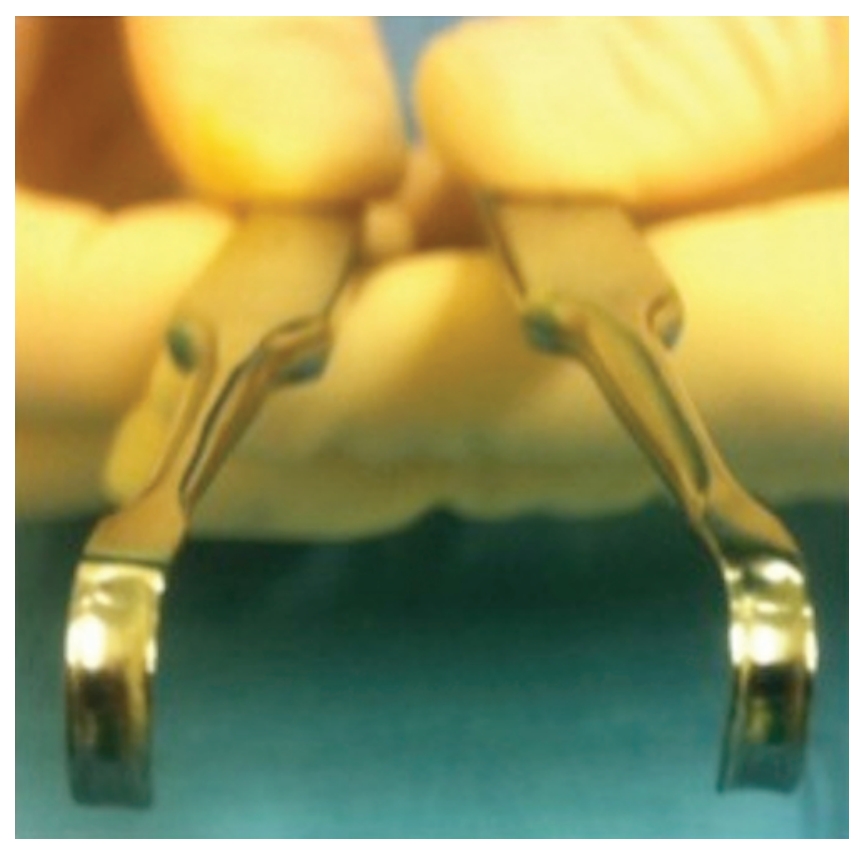

FIG. 3. Photograph showing 3-mm Ragnell retractors. Figure is available in color online only. 


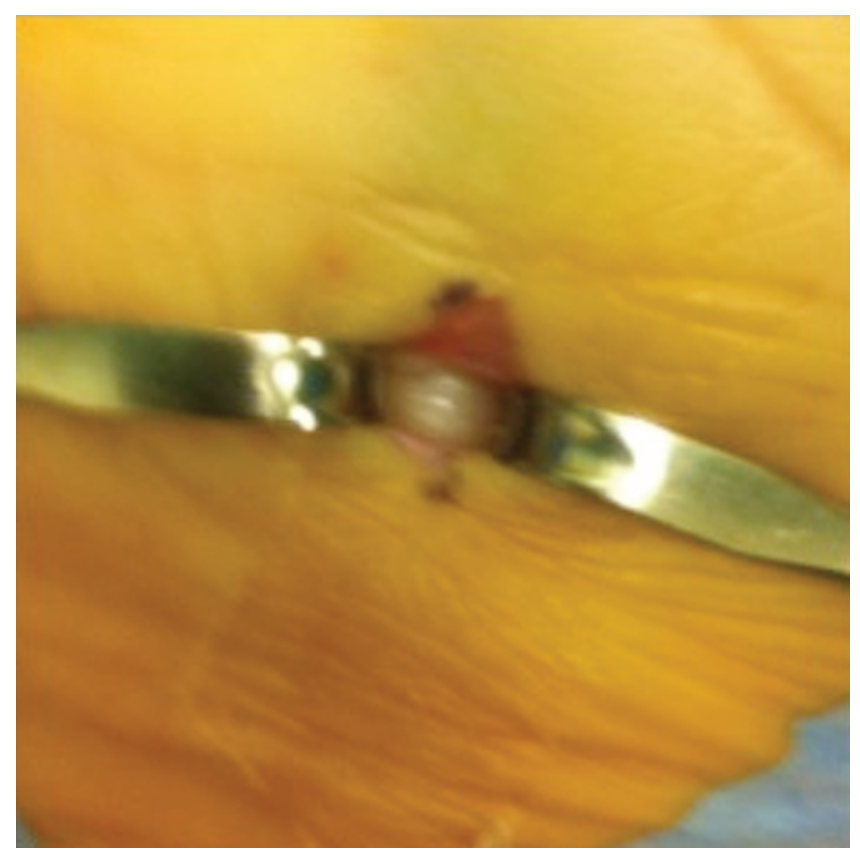

FIG. 4. Photograph showing direct vision of PF. Figure is available in color online only.

wrist crease. Samarakoon et al. ${ }^{28}$ revealed that the palmar incision must not be extended more than $8.16 \mathrm{~mm}$ from the proximal border of the TCL, to avoid inadvertently dividing the palmar cutaneous branch. Therefore, it is possible to avoid injuries of the recurrent branch and palmar cutaneous branch of the median nerve through a longitudinal palmar incision placed $5 \mathrm{~mm}$ ulnar and $6 \mathrm{~mm}$ radial to the junction between the longitude of the third finger and distal skin crease and extended not more than $8.16 \mathrm{~mm}$ proximally from the corresponding TCL border (safe area). ${ }^{28,35}$

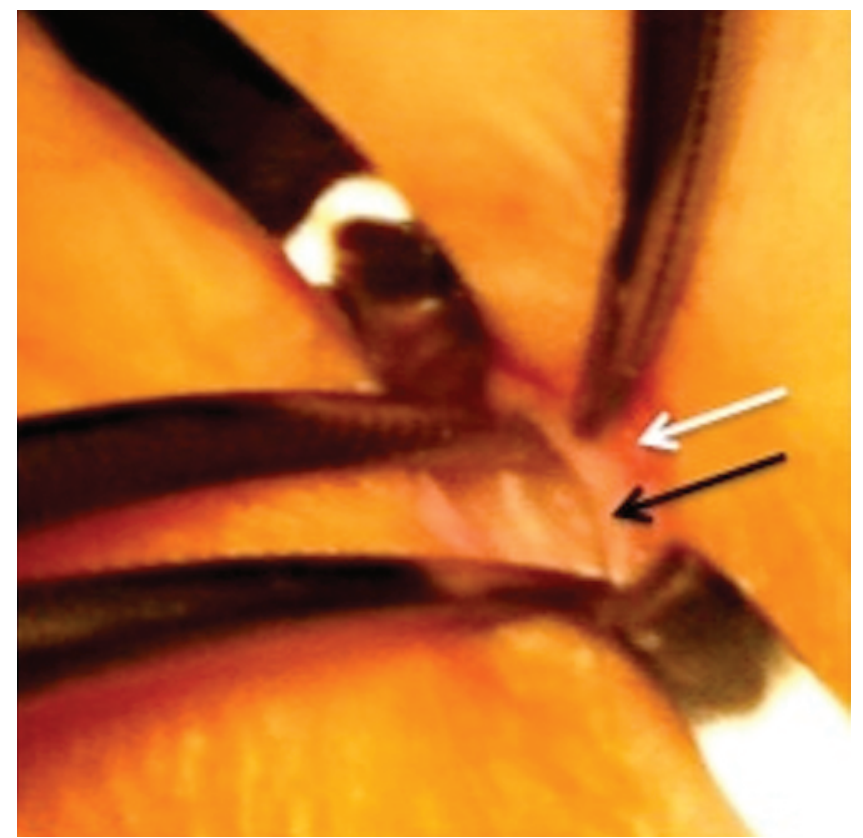

FIG. 5. Photograph showing PF (white arrow) reached and lifted up; subsequently the creation of a way to reach the TCL (black arrow), and the realization of the first tunnel. Figure is available in color online only.

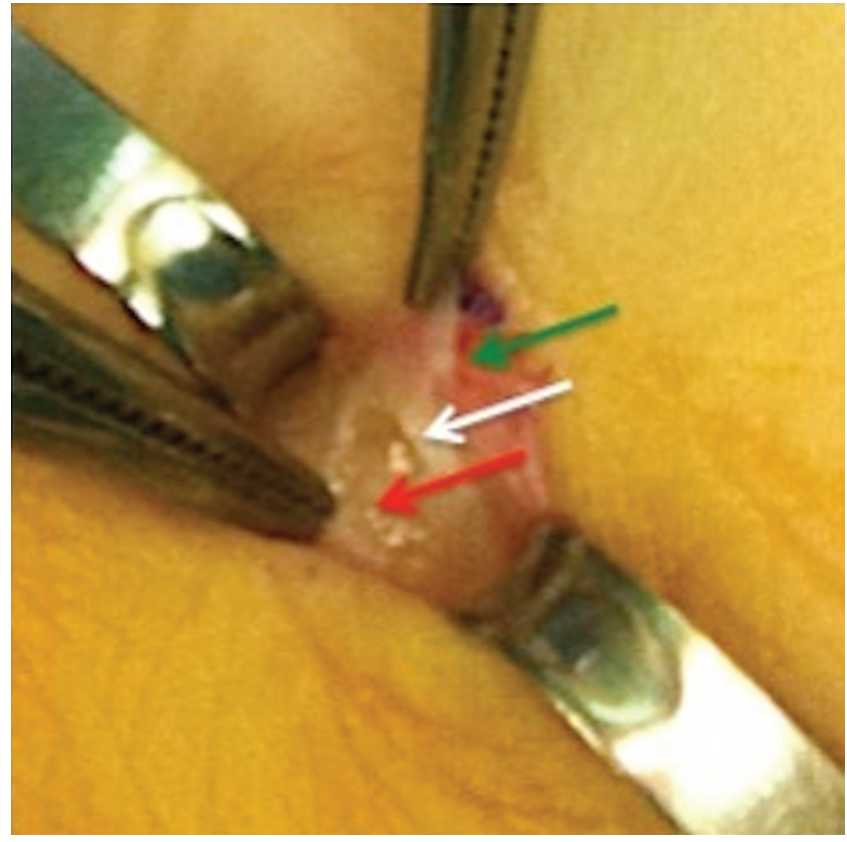

FIG. 6. Photograph showing PF (green arrow), TCL (white arrow), and median nerve (red arrow). Figure is available in color online only.

Furthermore, it must be considered that an incomplete section of the TCL is a current problem, common to both minimally invasive and open techniques. ${ }^{26}$ However, in the first approach the risk of an incomplete release is due to inadequate visualization of the TCL.${ }^{26}$ On the contrary, the DTT does not require a global and direct visualization of the ligament for its total section to be performed. In fact, the tunnels above and below the TCL allow the placement of safety jaw scissors and the TCL can be safety dissected, although under indirect visualization. Before

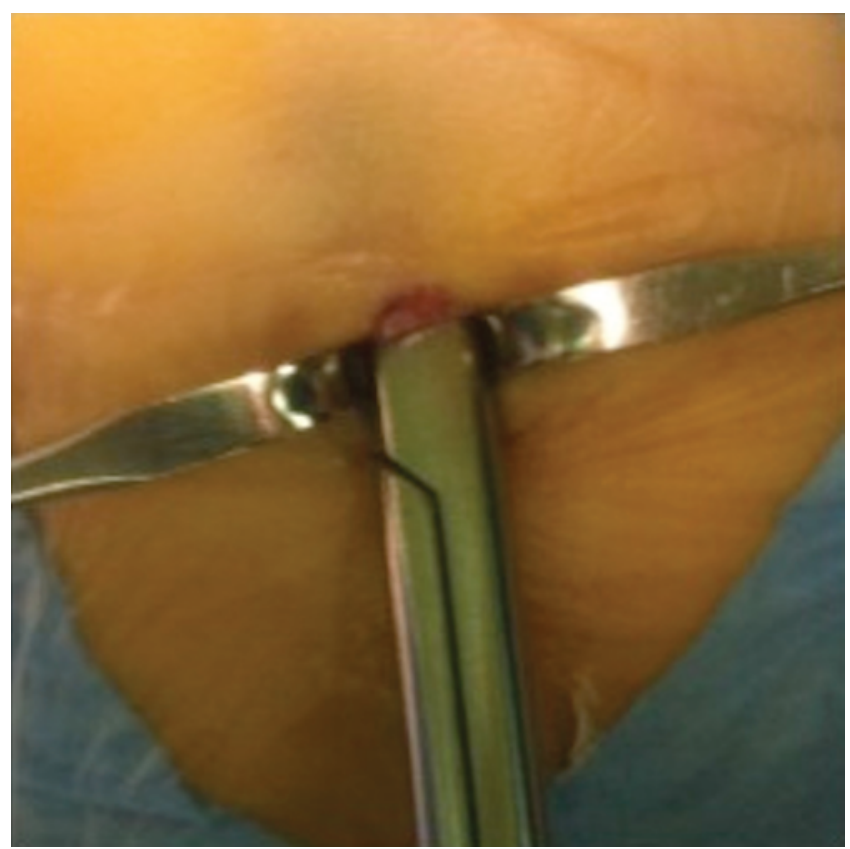

FIG. 7. Photograph showing the realization of the tunnels by blunt dissection. Figure is available in color online only. 


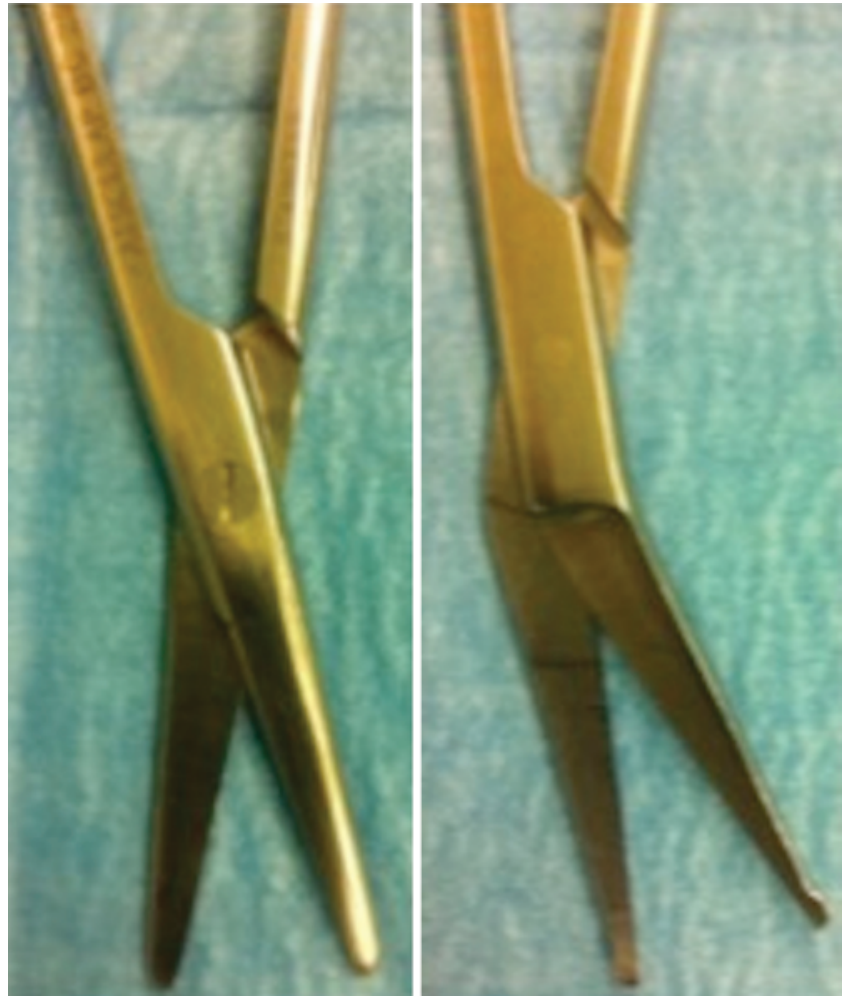

FIG. 8. Photographs showing dissecting scissors. Figure is available in color online only.

surgery it is mandatory to use the hook of the hamate as a landmark, to avoid damage to the superficial palmar arch and to obtain a complete TCL blind dissection. ${ }^{6}$ In fact, the distal aspect of the retinaculum lies $1 \mathrm{~cm}$ distal to the hamate hook, and the position of the superficial palmar arch lies approximately $2.5 \mathrm{~cm}$ distal to the hamate hook.

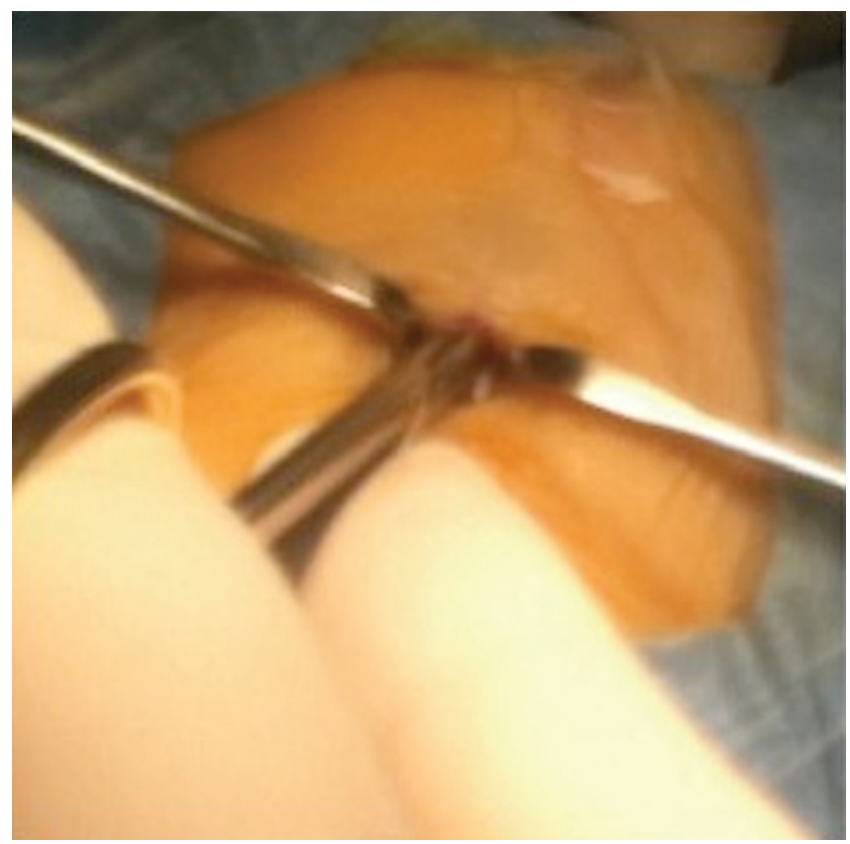

FIG. 9. Photograph showing scissors inserted in the anatomical binary created between the 2 tunnels. Figure is available in color online only.

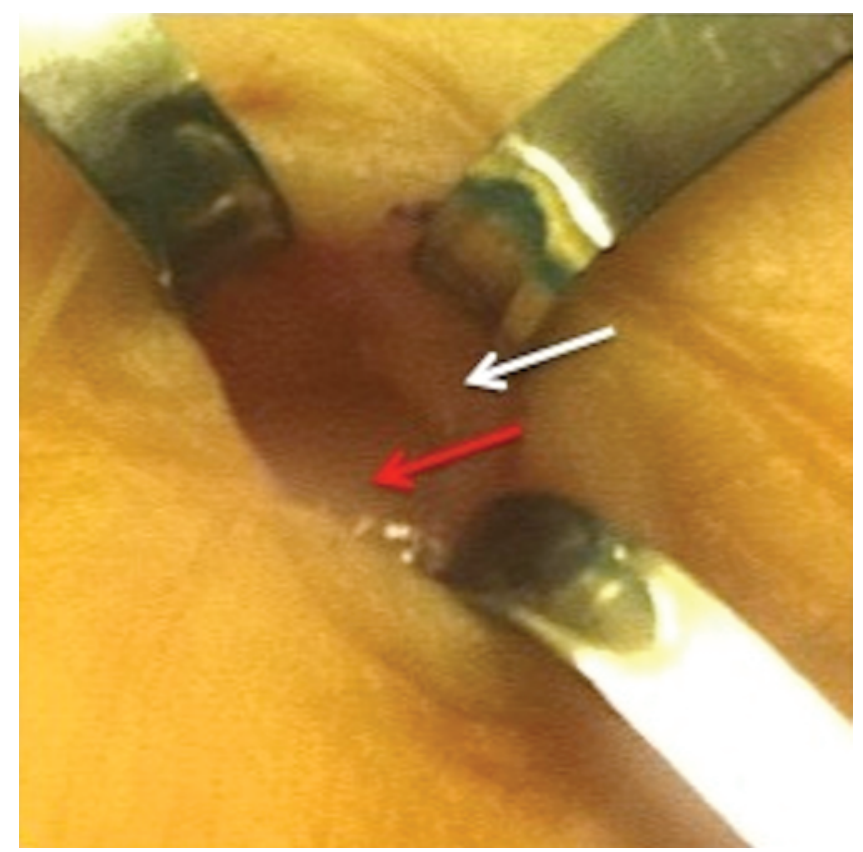

FIG. 10. Photograph showing TCL section: median nerve (red arrow) and PF (white arrow). Figure is available in color online only.

It is possible to mark on the palm of the hand the position of the superficial palmar arch and distal extent of the retinaculum. ${ }^{6-8}$ Because the mean length of the flexor retinaculum is $2.7 \mathrm{~cm},{ }^{28}$ it is possible to completely dissect the TCL without the risk of superficial palmar arch damage. During surgery it is also possible to perform an ultrasonographic evaluation to assess the complete section of the TCL. In case of damage to the superficial palmar arch, it is mandatory to obtain hemostasis through compression and topical hemostatic agents; otherwise it could be necessary to convert to the open approach.

The incision was closed with an intradermal interrupted suture (6-0 absorbable material) (Fig. 11) and covered with a soft dressing. A compressive wrap and ice were applied for 30 minutes. The patients were encouraged to cautiously move their fingers and wrist early after the operation, without wearing any brace.

\section{Standard Technique}

Standard open median nerve decompression ${ }^{25}$ was done via an interthenar approach. A longitudinal incision was made (mean length $3 \pm 0.5 \mathrm{~cm}$ ). It extended distally to the distal wrist crease, along a longitudinal line virtually drawn from the third web space to the wrist. . $^{1,5}$ Subsequently, subcutaneous fat was exposed and 2 small retractors were used to reach the longitudinally oriented fibers of the PF, which was finally incised. ${ }^{25}$ Through 2 retractors placed deep to the fascial edges, the transverse fibers of the TCL became identifiable. ${ }^{25}$ The TCL was divided longitudinally along its ulnar aspect, from distal to proximal. ${ }^{25}$

\section{Results}

The dominant limb and the nondominant one were involved in $85 \%$ and $15 \%$ of the patients, respectively. The 


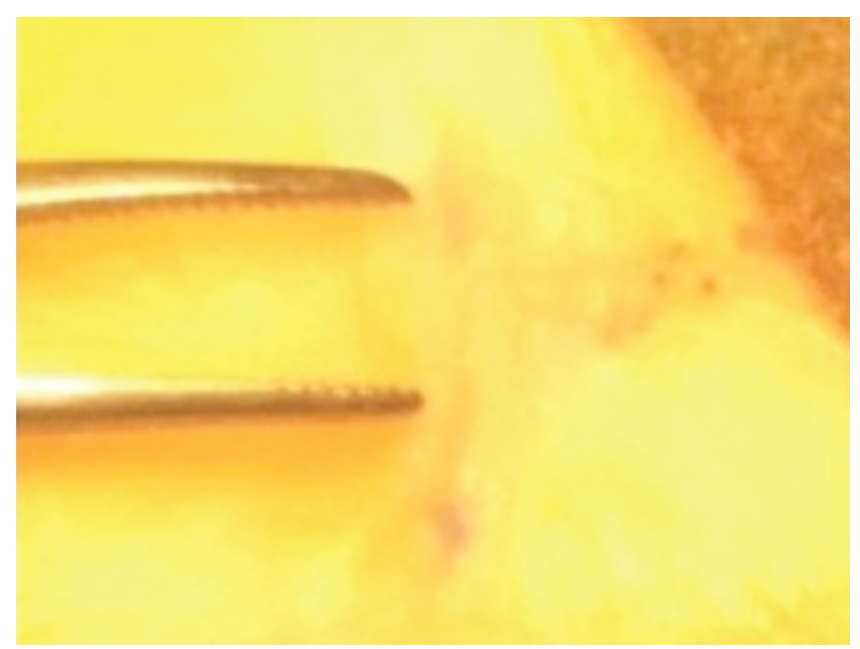

FIG. 11. Photograph showing final intradermal suture. Figure is available in color online only.

mean time of surgery was $18.2 \pm 5$ min in Group A and $13.9 \pm 2$ min in Group B (control) (Table 2). Preoperative clinical evaluation and postoperative follow-up were performed using the BCTSQ, evaluating the "quintet symptoms" (wrist pain, night pain, numbness, stiffness, and weakness). ${ }^{2}$

Preoperative wrist pain, night pain, and numbness were the most troublesome symptoms in our patients' opinion, and they showed the highest prevalence. After surgical treatment, clinical improvement was obtained in both groups, but with several differences.

Wrist pain and stiffness were less intense in Group A, with lower BCTSQ scores since the end of the 2nd week (mean values: $12.7 \pm 1.4$ vs $27.2 \pm 3.1$ for Group A and B, respectively). At Week 4, wrist pain and nocturnal pain had almost disappeared in the patients in Group A, who reported lesser weakness than those in Group B (mean values: $6.4 \pm 1.3$ vs $16.2 \pm 2.2$ for Group $A$ and $B$, respectively). The BCTSQ scores at Month 3 were globally lower in Group A (mean values: $2.1 \pm 1.1$ vs $8.3 \pm 1.8$ for Group $\mathrm{A}$ and $\mathrm{B}$, respectively), whereas at Month 6 (mean values: $0.8 \pm 0.1$ vs $8.1 \pm 1.2$ for Group A and B, respectively) and even more so at Month 12, this difference was significantly reduced (mean value: $0.1 \pm 0.03$ vs $1.9 \pm 0.9$ for Group A and $\mathrm{B}$, respectively) (Table 3 ).

According to the pVAS, postoperative pain was significantly less in Group A. The mean pVAS value was $2.1 \pm$ 0.5 in Group A and $4.9 \pm 0.5$ in Group B. The average time required to return to work was $10.2 \pm 3.6$ days in Group A and $25.3 \pm 5.2$ days in Group B.

Aesthetic aspects were not neglected (Fig. 12): we evaluated the aesthetic outcomes according to an aVAS, asking patients to quantify from 1 to 10 their satisfaction about the surgical scar. At Month 12, the mean value was 9.4 \pm 0.5 in Group A and $6.4 \pm 0.5$ in Group B (Table 2). In the DTT group there were neither neurovascular complications nor tendon injuries, whereas in the open median nerve decompression group, 4 cases of iatrogenic injuries of the palmar arches branches occurred, leading to more intraoperative bleeding and longer surgical time.

A clinical definition was used to recognize hypertro-
TABLE 2. Comparison of results in patients with CTS*

\begin{tabular}{cccc}
\hline Group & Mean Op Time & Postop pVAS Score & aVAS Score at Mo 12 \\
\hline A & $18.2 \pm 5$ min & $2.1 \pm 0.5$ & $9.4 \pm 0.5$ \\
\hline B & $13.9 \pm 2$ min & $4.9 \pm 0.5$ & $6.4 \pm 0.5$ \\
\hline
\end{tabular}

* Values are expressed as the mean \pm SD.

phic scars and keloids. ${ }^{34}$ Hypertrophic scars remain within the borders of the early surgical wound. On the contrary, keloids extend beyond the borders of the wound. A scar was defined as painful if the patient reported surgical scar pain or discomfort at the end of the wound healing process. ${ }^{34}$ In Group A only 2 cases of hypertrophic scars were observed, but no painful scars, whereas in Group B there were 13 cases of hypertrophic and 11 cases of painful scars.

Only 1 patient treated by DTT underwent open revision surgery, whereas this occurred in 12 cases in Group B. Furthermore, in Group A no pillar pain phenomenon was noticed, contrary to Group B (19 cases). No infection occurred in either group (Table 4). Finally, with regard to the global satisfaction, the patients in Group A showed better outcomes, especially in the earlier stages of the follow-up. Statistical analyses were performed independently by a nonclinical investigator assistant. The Student t-test and ANOVA were used and the results were considered statistically significant if the $p$ value was $\leq 0.05$ for continuous variables. The data were analyzed using standard statistical software. The statistical analyses allowed us to determine that the differences between the 2 groups are not random and that therefore the null hypothesis (that is, no differences between the 2 groups) must be rejected.

\section{Discussion}

Carpal tunnel syndrome is the most common canalicular syndrome. To reduce complications and adverse events related to the surgical procedures, several techniques have been described over the years: classic or standard open approaches, single or multiportal endoscopic approaches, and mini-open approaches. . $^{4,13,20,33}$

The standard technique was considered the best approach in the past, and thus it represents the basis for comparison. Although it allows a direct visualization of the neurovascular structures, it has been associated with several complications such as painful scars, neuromas, and pillar pain. ${ }^{25,29}$ For these reasons the endoscopic approaches were developed. DaSilva et al. ${ }^{9}$ showed that endoscopic surgery saves unmyelinated nerve fibers at the interthenar fold. These fibers derive from the cutaneous palmar branches of the median nerve, located in the loose connective tissue that is situated superficial to flexor reti-

TABLE 3. Comparison of BCTSQ scores in patients with CTS*

\begin{tabular}{cccccc}
\hline & \multicolumn{5}{c}{ Time Postop \& BCTSQ Score } \\
\cline { 2 - 6 } Group & Wk 2 & Wk 4 & Mo 3 & Mo 6 & Mo 12 \\
\hline A & $12.7 \pm 1.4$ & $6.4 \pm 1.3$ & $2.1 \pm 1.1$ & $0.8 \pm 0.1$ & $0.1 \pm 0.03$ \\
\hline B & $27.2 \pm 3.1$ & $16.2 \pm 2.2$ & $8.3 \pm 1.8$ & $8.1 \pm 1.2$ & $1.9 \pm 0.9$ \\
\hline
\end{tabular}

* Values are expressed as the mean \pm SD. 


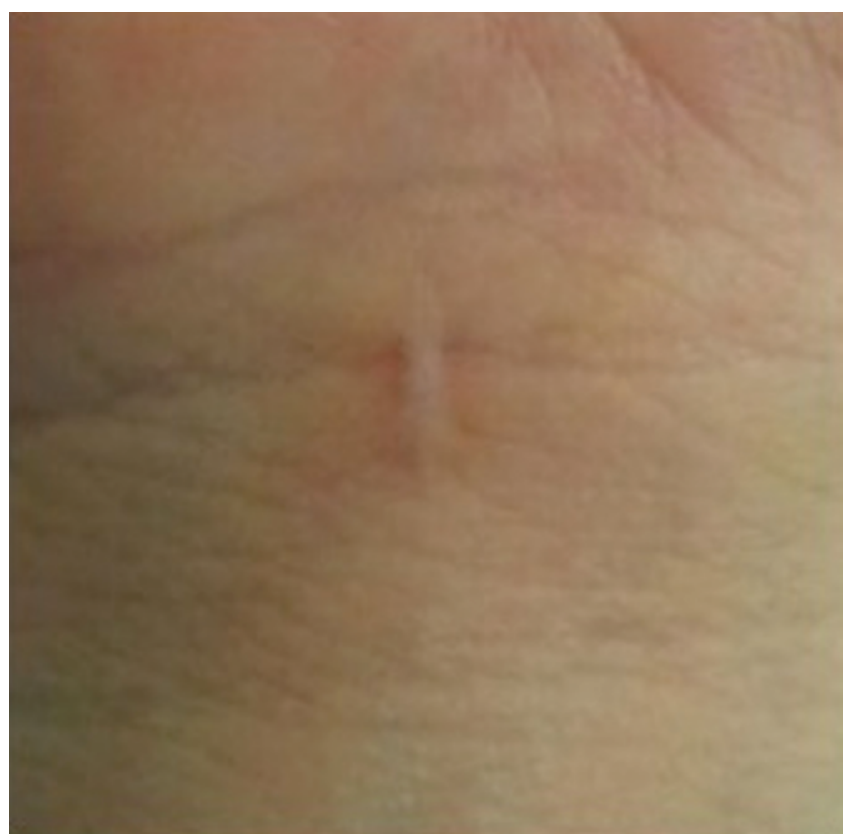

FIG. 12. Photograph showing surgery scar at follow-up clinic visit in a control patient at Month 3 . Figure is available in color online only.

naculum. It must be considered that other structures such as the vascular branches of the superficial palmar arch, placed within a protective layer of adipose tissue, can also be damaged in this type of approach. ${ }^{27}$ Serra et al. ${ }^{30}$ established that there is a direct relationship between postoperative wrist pain and the extent of subcutaneous adipose tissue damage.

Other studies compared the standard and endoscopic approaches. The short-term results of the 2 techniques were similar, but the second group showed faster recovery times, although some patients required a revision surgery. In fact the endoscopic techniques are not free from complications. Although these endoscopic approaches showed a reduction of recovery time, the most recent studies have detected postoperative complications related to the incision site and to the surgical technique, such as scar tenderness, persistent weakness, and neurovascular injury. ${ }^{17,21,32}$

The minimally invasive techniques represent an alternative to obtain an improved balance between the "tissue-sparing surgery" and the respect for locoregional anatomy. Bromley ${ }^{4}$ and Wilson ${ }^{36}$ reported excellent results using minimally invasive techniques, without significant complications. Hamed and Harfoushi ${ }^{15}$ performed a minitransverse incision, showing that this approach is safe and aesthetically satisfying in $94 \%$ of patients.

It was demonstrated that the smaller the incision is, the faster the recovery time, but it is mandatory to define the

TABLE 4. Comparison of complications in patients with CTS

\begin{tabular}{ccccccc}
\hline Group & $\begin{array}{c}\text { VPAB } \\
\text { Injuries }\end{array}$ & $\begin{array}{c}\text { Hypertrophic } \\
\text { Scars }\end{array}$ & $\begin{array}{c}\text { Painful } \\
\text { Scars }\end{array}$ & Revisions & $\begin{array}{c}\text { Pillar } \\
\text { Pain }\end{array}$ & Infections \\
\hline A & 0 & 2 & 0 & 1 & 0 & 0 \\
\hline B & 4 & 13 & 11 & 12 & 19 & 0 \\
\hline
\end{tabular}

$\mathrm{VPAB}=$ vascular palmar arches branches. access point and the features of surgical technique. Other studies compared minimally invasive techniques and standard open approaches, showing that recovery time was reduced by an average of 20 days. ${ }^{19}$

Lee and Strickland ${ }^{20}$ showed that the minimally invasive palmar approach is associated with satisfying results. In fact, the authors proved that preservation of the fascial convergence between the thenar and the hypothenar and the avoidance of a skin incision that crosses the wrist crease are the most important points for quick postoperative recovery. These findings led us to develop a new technique for the neurolysis of the median nerve. The DTT allows dissection of the TCL through a very small longitudinal skin incision $(0.6 \pm 0.05 \mathrm{~cm})$ that is able to respect the neurovascular structures, whose integrity is mandatory to avoid short- and long-term complications.

In our experience, by limiting the incision length, respecting the palmar subcutaneous space, and remaining below the PF, it possible to reduce inflammation and bleeding, and therefore the postoperative pain and weakness, as well as the medium- and long-term complications and, consequently, the risk of recurrence. These data were recently confirmed by Klein et al. ${ }^{18}$

There are several differences between the technique described by Klein and the DTT; these are as follows. 1) The Klein technique involves a palmar incision, whereas DTT entails a wrist incision, distally to the proximal wrist crease. 2) The Klein technique provides the division of the whole PF, to obtain a direct visualization of the TCL. According to our approach, only a small transverse incision (about $5 \mathrm{~mm}$ ) is done where the antebrachial fascia continues with the $\mathrm{PF}$, which remains intact. In this way the PF can be lifted up to create, by blunt dissection, the first "subfascial" tunnel. 3) According to the Klein technique the TCL is dissected under direct observation, whereas in our study the TCL is divided blindly. 4) The technique described by Klein et al. assumes that scissors are used to divide the TCL distally before and proximally after, using the slit forming a " $V$ " to guide division, under direct observation. According to our technique, the TCL is divided from distal to proximal in a single surgical session. 5) The Klein technique does not entail the realization, by blunt dissection, of 2 tunnels necessary to guide the blind division of the TCL, as in DTT. 6) According to Klein, the division of the distal part of the TCL is the guide to subsequently perform the section of its proximal part. On the contrary, according to the DTT, the 2 tunnels act as guides for the total distal to proximal division of the ligament.

The DTT is a safe operation: it follows the anatomical safe zones according to Martin, and it respects the PF and the subcutaneous tissue to avoid the neurovascular structures. ${ }^{23}$ Naturally, it is mandatory to perform a preoperative ultrasound evaluation (to exclude anatomical variations of the median nerve and the surrounding structures, flexors tenosynovitis, and space-occupying lesions ${ }^{16}$ ) as well as to use cutaneous landmarks (to avoid damage to either the palmar cutaneous branch of the median nerve or the vascular branches of the superficial palmar arch).

\section{Conclusions}

Each section of the BCTSQ showed better scores in 
patients treated using the DTT compared with patients treated using the standard open approach. There were no complications, either intraoperative or postoperative. There were no CTS recurrences. All patients showed a high global satisfaction level, according to the scales previously mentioned.

Therefore, our technique represents a safe and effective approach for the CTS treatment, with clinically, functionally, and aesthetically satisfactory outcomes, as proved by questionnaire results and, moreover, by faster recovery times.

\section{References}

1. Alizadeh K, Lahiji F, Phalsaphy M: Safety of carpal tunnel release with a short incision. A cadaver study. Acta Orthop Belg 72:415-419, 2006

2. Aslani HR, Alizadeh K, Eajazi A, Karimi A, Karimi MH, Zaferani Z, et al: Comparison of carpal tunnel release with three different techniques. Clin Neurol Neurosurg 114:965968, 2012

3. Bland JD: A neurophysiological grading scale for carpal tunnel syndrome. Muscle Nerve 23:1280-1283, 2000

4. Bromley GS: Minimal-incision open carpal tunnel decompression. J Hand Surg Am 19:119-120, 1994

5. Chaynes P, Bécue J, Vaysse P, Laude M: Relationships of the palmar cutaneous branch of the median nerve: a morphometric study. Surg Radiol Anat 26:275-280, 2004

6. Cobb TK, Cooney WP, An KN: Clinical location of hook of hamate: a technical note for endoscopic carpal tunnel release. J Hand Surg Am 19:516-518, 1994

7. Cobb TK, Cooney WP, An KN: Relationship of deep structures of the hand and wrist to topographical landmarks. $\mathbf{J}$ Clin Anat 6:300-307, 1993

8. Cobb TK, Dalley BK, Posteraro RH, Lewis RC: Anatomy of the flexor retinaculum. J Hand Surg Am 18:91-99, 1993

9. DaSilva MF, Moore DC, Weiss AP, Akelman E, Sikirica M: Anatomy of the palmar cutaneous branch of the median nerve: clinical significance. J Hand Surg Am 21:639-643, 1996

10. Dellon AL, Chang BW: An alternative incision for approaching recurrent median nerve compression at the wrist. Plast Reconstr Surg 89:576-578, 1992

11. Dellon AL, Keller KM: Computer-assisted quantitative sensorimotor testing in patients with carpal and cubital tunnel syndromes. Ann Plast Surg 38:493-502, 1997

12. Duncan KH, Lewis RC Jr, Foreman KA, Nordyke MD: Treatment of carpal tunnel syndrome by members of the American Society for Surgery of the Hand: results of a questionnaire. J Hand Surg Am 12:384-391, 1987

13. Einhorn N, Leddy JP: Pitfalls of endoscopic carpal tunnel release. Orthop Clin North Am 27:373-380, 1996

14. Franzblau A, Werner RA: What is carpal tunnel syndrome? JAMA 282:186-187, 1999

15. Hamed SA, Harfoushi FZ: Carpal tunnel release via miniopen wrist crease incision: procedure and results of four years clinical experience. Pak J Med Sci 22:367-372, 2006

16. Iannicelli E, Chianta GA, Salvini V, Almberger M, Monacelli G, Passariello R: Evaluation of bifid median nerve with sonography and MR imaging. J Ultrasound Med 19:481-485, 2000

17. Jugovac I, Burgić N, Mićović V, Radolović-Prenc L, Uravić M, Golubović V, et al: Carpal tunnel release by limited palmar incision vs traditional open technique: randomized controlled trial. Croat Med J 43:33-36, 2002

18. Klein RD, Kotsis SV, Chung KC: Open carpal tunnel release using a 1-centimeter incision: technique and outcomes for 104 patients. Plast Reconstr Surg 111:1616-1622, 2003
19. Lee H, Jackson TA: Carpal tunnel release through a limited skin incision under direct visualization using a new instrument, the carposcope. Plast Reconstr Surg 98:313-320, 1996

20. Lee WP, Strickland JW: Safe carpal tunnel release via a limited palmar incision. Plast Reconstr Surg 101:418-426, 1998

21. Macdermid JC, Richards RS, Roth JH, Ross DC, King GJ: Endoscopic versus open carpal tunnel release: a randomized trial. J Hand Surg Am 28:475-480, 2003

22. MacDonald RI, Lichtman DM, Hanlon JJ, Wilson JN: Complications of surgical release for carpal tunnel syndrome. J Hand Surg Am 3:70-76, 1978

23. Martin CH, Seiler JG III, Lesesne JS: The cutaneous innervation of the palm: an anatomic study of the ulnar and median nerves. J Hand Surg Am 21:634-638, 1996

24. Mavrogenis AF, Papagelopoulos PJ, Ignatiadis IA, Spyridonos SG, Efstathopoulos DG: Complications of open carpal tunnel surgery: avoiding the pitfalls. Eur J Orthop Surg Traumatol 19:11-17, 2009

25. Phalen GS, Gardner WJ, La Londe AA: Neuropathy of the median nerve due to compression beneath the transverse carpal ligament. J Bone Joint Surg Am 32:109-112, 1950

26. Rodner CM, Katarincic J: Tech Orthop 21:3-11, 2006

27. Sacks JM, Kuo YR, Mclean K, Wollstein R, Lee WP: Anatomical relationships among the median nerve thenar branch, superficial palmar arch, and transverse carpal ligament. Plast Reconstr Surg 120:713-718, 2007

28. Samarakoon LB, Guruge MH, Jayasekara M, Malalasekera AP, Anthony DJ, Jayasekara RW: Anatomical landmarks for safer carpal tunnel decompression: an experimental cadaveric study. Patient Saf Surg 8:8, 2014

29. Semple JC, Cargill AO: Carpal-tunnel syndrome. Results of surgical decompression. Lancet 1:918-919, 1969

30. Serra JM, Benito JR, Monner J: Carpal tunnel release with short incision. Plast Reconstr Surg 99:129-135, 1997

31. Steinberg DR: Surgical release of the carpal tunnel. Hand Clin 18:291-298, 2002

32. Thoma A, Veltri K, Haines T, Duku E: A meta-analysis of randomized controlled trials comparing endoscopic and open carpal tunnel decompression. Plast Reconstr Surg 114:1137-1146, 2004

33. Trumble TE, Diao E, Abrams RA, Gilbert-Anderson MM: Single-portal endoscopic carpal tunnel release compared with open release: a prospective, randomized trial. J Bone Joint Surg Am 84:1107-1115, 2002

34. Urioste SS, Arndt KA, Dover JS: Keloids and hypertrophic scars: review and treatment strategies. Semin Cutan Med Surg 18:159-171, 1999

35. Watchmaker GP, Weber D, Mackinnon SE: Avoidance of transection of the palmar cutaneous branch of the median nerve in carpal tunnel release. J Hand Surg Am 21:644650,1996

36. Wilson KM: Double incision open technique for carpal tunnel release: an alternative to endoscopic release. J Hand Surg Am 19:907-912, 1994

\section{Author Contributions}

Conception and design: Vanni, Magliani. Acquisition of data: Vanni, Sirabella, Magliani. Analysis and interpretation of data: Vanni, Sirabella, Magliani. Drafting the article: Vanni, Salini, Magliani. Critically revising the article: Galzio, Magliani. Reviewed submitted version of manuscript: all authors. Study supervision: Galzio, Magliani.

\section{Correspondence}

Daniele Vanni, Orthopaedic and Traumatology Department, "G. D’Annunzio" University, Via Dei Vestini 65100, Chieti, Italy. email: danielevannimd@libero.it. 